\title{
Orthopaedic Foot and Ankle Surgery Fellowship Directors Are Typically White Men in Their Early 50s With Strong Achievements in Research
}

\author{
Muhammad Ali Elahi, B.S., M. Lane Moore, B.S., Matthew K. Doan, B.S., \\ Jordan R. Pollock, B.S., Jeffrey D. Hassebrock, M.D., Justin L. Makovicka, M.D., M.B.A., \\ Joseph C. Brinkman, M.D., and Karan A. Patel, M.D.
}

\begin{abstract}
Purpose: To determine the objective characteristics of orthopaedic foot and ankle fellowship directors (FDs) by concentrating on the demographic characteristics, academic background, institutional history, research experience, and professional affiliations of these leaders. Methods: Data for each FD were collected by searching institutional biographies, personal websites, or publicly available curricula vitae. Data collection included the following variables: age, sex, race/ethnicity, previous training institutions, residency and fellowship graduation years, advanced degrees, military affiliation, institutional loyalty, year hired, FD career timeline, total number of publications, total number of citations, and $h$-index. Results: Of the 47 FDs, $44(93.6 \%)$ were men and $3(6.4 \%)$ were women. The mean age was $50.8 \pm 9.4$ years. Most orthopaedic foot and ankle FDs were white $(\mathrm{n}=42,89.4 \%)$, followed by Asian $(\mathrm{n}=4,8.5 \%)$ and black or African American $(\mathrm{n}=1,2.1 \%)$. The mean Scopus $h$-index, total number of publications, and total number of citations for all foot and ankle FDs were $13.3 \pm 9.5,47.5 \pm 45.8$, and $898.1 \pm 1,040.3$, respectively. Among all foot and ankle FDs, the mean tenure in the FD position was $5.8 \pm 4.6$ years. Conclusions: Orthopaedic foot and ankle FDs are primarily white men in their 50s, with minimal female and minority representations. These FDs are distinguished by their high level of research productivity. Additionally, orthopaedic foot and ankle training backgrounds seem to play an important role, given that most of the appointed FDs trained in only a few select programs. Clinical Relevance: This study outlines some of the most important characteristics among foot and ankle FDs and identifies important disparities within this population of leaders that may have detrimental effects on the field.
\end{abstract}

$\mathbf{O}$ rthopaedic surgery has seen a substantial rise in the number of surgeons pursuing fellowship training after residency over the past couple of

From Mayo Clinic Alix School of Medicine, Scottsdale, Arizona, U.S.A. (M.A.E., M.L.M., M.K.D., J.R.P.); and Department of Orthopedic Surgery, Mayo Clinic, Phoenix, Arizona, U.S.A. (J.D.H., J.L.M., J.C.B., K.A.P.).

The authors report the following potential conflicts of interest or sources of funding: J.D.H. receives educational support payments from Goode Surgical, outside the submitted work. K.A.P. receives educational support payments from Arthrex, outside the submitted work. Full ICMJE author disclosure forms are available for this article online, as supplementary material.

Approval from our local institutional review board was deemed exempt for this study as all study data is publicly available and does not contain patient information.

Received March 26, 2021; accepted July 26, 2021.

Address correspondence to Karan A. Patel, M.D., Department of Orthopedic Surgery, Mayo Clinic, 5777 E Mayo Blvd, Phoenix, AZ 85054, U.S.A. E-mail: patel.karan@mayo.edu

(C) 2021 THE AUTHORS. Published by Elsevier Inc. on behalf of the Arthroscopy Association of North America. This is an open access article under the CC BY-NC-ND license (http://creativecommons.org/licenses/by-nc-nd/4.0/). 2666-061X/21487

https://doi.org/10.1016/j.asmr.2021.07.018 decades. ${ }^{1-3}$ As of 2013, approximately $90 \%$ of all orthopaedic surgeons applying for board certification had completed a fellowship. This represented a substantial increase over the $76 \%$ rate of orthopaedic fellowship training reported in 2003. ${ }^{4}$ As fellowship training becomes increasingly popular in the field of orthopaedic surgery, the influence of fellowship directors (FDs) on current and future orthopaedic surgeons continues to rise. FDs are often leaders within their field and often possess unique clinical, research, academic, and professional backgrounds that are worthy of recognition.

Numerous previous analyses have attempted to describe and characterize orthopaedic applicants and trainees in an attempt to understand a wide range of factors that lead to success in the highly competitive field. $^{2,5-10}$ However, a paucity of literature exists examining the achievements and qualities of orthopaedic leadership. Among the limited available research, some studies have highlighted the sex disparity within orthopaedics and its leadership. ${ }^{1-13}$ Other studies have endeavored to describe the leadership characteristics of 
plastic surgery FDs and orthopaedic FDs in adult reconstructive surgery and spine surgery. ${ }^{14-16}$

Orthopaedic foot and ankle FDs are hypothesized to possess a broad repertoire of leadership skills and professional, academic, and clinical achievements. However, the objective benchmarks that set these accomplished FDs apart from their peers have not been elucidated. The purpose of this study was to determine the objective characteristics of orthopaedic foot and ankle FDs by concentrating on the demographic characteristics, academic background, institutional history, research experience, and professional affiliations of these leaders. The hypothesis of this investigation was that if the orthopaedic foot and ankle FDs included in this analysis were similar in prestige and accomplishment to those in other orthopaedic fields, then they would possess high levels of research productivity and output. We also hypothesized that the FDs would be homogeneous in their racial/ethnic makeup and would be predominantly male individuals, which reflects the field of orthopaedics as a whole.

\section{Methods}

The American Orthopaedic Foot \& Ankle Society (AOFAS) Orthopaedic Foot and Ankle Fellowship Programs listing for 2020-2021 was reviewed to compile a list of all Accreditation Council for Graduate Medical Education (ACGME)-accredited foot and ankle fellowships in the United States (accessed December 2020). ${ }^{17}$ This listing from AOFAS was crossreferenced with the SF Match 2020 fellowship listing (SF Match-Residency and Fellowship Matching Services, San Francisco, CA) to ensure accuracy. ${ }^{18}$ The FD from each program was identified from the AOFAS and SF Match foot and ankle fellowship listings. Next, demographic, educational, and professional background data were collected for each FD by review of institutional biographies, publicly available curricula vitae (CVs), or personal websites. If all desired information was not present on institutional or personal websites or in CVs, e-mail questionnaires that requested the missing pieces of data were sent to fellowship program administrators or coordinators. If there was no response to the initial e-mail and 1 follow-up e-mail, a phone call was made to the program administrator or coordinator.

Data collected for each orthopaedic foot and ankle FD included the following: age, sex, race/ethnicity, past medical school program, past residency training location, past fellowship training location, residency and fellowship graduation years, additional advanced degrees, military affiliation, institutional loyalty, year hired by current institution, time since residency and fellowship completion until FD appointment, and length of time in FD role. Furthermore, each FD's $h$-index, total number of publications, and total number of citations were collected in an effort to measure research productivity and impact within the field.

The $h$-index is an objective measurement of an individual's scientific productivity and impact. The $h$-index is defined as the maximum value of $h$ such that the author in question has published $h$ scientific manuscripts that have all been cited a minimum of $h$ times. ${ }^{19}$ For example, an author with an $h$-index of 20 must have 20 published scientific manuscripts, each with a minimum of 20 citations. To obtain the data for the $h$-index, total number of publications, and total number of citations, the FD's name was searched on the Scopus database (Elsevier, Waltham, MA).$^{20}$ The Scopus database is composed of a vast record of peer-reviewed literature and charts scientific productivity metrics such as the $h$-index, total number of publications, and total number of citations for authors. Publications were defined as pieces of scientific literature for which the author's name was contained anywhere on the author line. The total number of citations was calculated by the Scopus database and was defined as the total number of citations in which the author was acknowledged for any of his or her scientific works.

Statistical analysis included the calculation of Pearson correlation coefficients and was performed using Microsoft Excel (Microsoft, Redmond, WA). The correlation coefficients calculated in this analysis were interpreted according to Mukaka's guide on correlation coefficient interpretation in medical research settings. ${ }^{21}$ Correlation coefficient values of less than $0.4,0.4$ to 0.7 , 0.7 to 0.9 , and greater than 0.9 are suggestive of weak, moderate, strong, and very strong positive correlations, respectively. ${ }^{22}$

\section{Results}

According to the AOFAS 2020-2021 Orthopaedic Foot and Ankle Fellowship Programs listing, there are a total of 47 accredited foot and ankle fellowship programs in the United States. In this analysis, data were collected for all 47 FDs associated with these accredited fellowship programs. However, all data points as outlined in the "Methods" section were not able to be found or obtained for $100 \%$ of FDs. Overall, 26 FDs $(55.3 \%)$ had complete data whereas the remaining 21 FDs had nearly complete or partially complete data. Therefore, some variables such as time from graduation until FD appointment $(57.4 \%$ complete), time from year of hire to FD appointment (57.4\% complete), and mean number of years in FD role $(59.6 \%)$ may be less representative of the entire orthopaedic foot and ankle FD population.

Of the 47 FDs in this analysis, $44(93.6 \%)$ were men and $3(6.4 \%)$ were women. The mean age of all FDs was $50.8 \pm 9.4$ years. A total of 6 FDs had 1 or more additional advanced degrees; 3 FDs had completed a master of public health, 2 had completed a master of science, and 1 had completed a master of business 
Table 1. Demographic Characteristics, Training and Research Background, Educational and Employment History, and Leadership Positions of Orthopaedic Foot and Ankle FDs

\begin{tabular}{|c|c|}
\hline & Data \\
\hline \multicolumn{2}{|l|}{ Overall leadership } \\
\hline Total No. of fellowship programs & 47 \\
\hline Total No. of FDs & 47 \\
\hline \multicolumn{2}{|l|}{ Sex, n $(\%)$} \\
\hline Male & $44(93.6)$ \\
\hline Female & $3(6.4)$ \\
\hline Doctor of philosophy & $0(0.0)$ \\
\hline Master of business administration & $1(2.1)$ \\
\hline Master of public health & $3(6.4)$ \\
\hline Master of science & $2(4.2)$ \\
\hline \multicolumn{2}{|l|}{ Training and research } \\
\hline Military affiliation, n (\%) & $3(6.4)$ \\
\hline American Indian or Alaskan Native & $0(0.0)$ \\
\hline Asian & $4(8.5)$ \\
\hline Black or African American & $1(2.1)$ \\
\hline Hispanic or Latino & $0(1.1)$ \\
\hline Native Hawaiian or other Pacific Islander & $0(0.0)$ \\
\hline White & $42(89.4)$ \\
\hline \multicolumn{2}{|l|}{ Education and employment progression } \\
\hline Residency graduation calendar year, mean & $2002(\mathrm{SD}, 9.9 \mathrm{yr})(\mathrm{n}=40)$ \\
\hline Fellowship graduation calendar year, mean & $2003(\mathrm{SD}, 9.8$ yr $)(\mathrm{n}=40)$ \\
\hline Time from fellowship graduation to FD appointment, mean \pm SD, yr & $11.5 \pm 9.1(\mathrm{n}=27)$ \\
\hline Time of FD employment at FD's current institution, mean \pm SD, yr & $12.4 \pm 7.4(\mathrm{n}=35)$ \\
\hline Time in FD role, mean $\pm S D$, yr & $5.8 \pm 4.6(\mathrm{n}=28)$ \\
\hline
\end{tabular}

FD, fellowship director; SD, standard deviation.

*Statistically significant.

administration. Of the FDs, $3(6.4 \%)$ had a military affiliation at one point in their career. The mean Scopus $h$-index, total number of publications, and total number of citations for all foot and ankle FDs were $13.3 \pm 9.5$, $47.5 \pm 45.8$, and 898.1 $\pm 1,040.3$, respectively (Table 1). The research metrics for the 10 most prolific researchers in this group of FDs are included in Table 2. Most orthopaedic foot and ankle FDs were white $(\mathrm{n}=42,89.4 \%)$, followed by Asian $(\mathrm{n}=4,8.5 \%)$ and black or African American ( $\mathrm{n}=1,2.1 \%)$.

The mean calendar years for the completion of orthopaedic residency training and fellowship training were 2002 (standard deviation, 9.9 years) and 2003 (standard deviation, 9.8 years), respectively. On average, it took $11.5 \pm 9.5$ years from fellowship training graduation until FD appointment. Among all foot and ankle FDs, the mean tenure in the FD position was $5.8 \pm 4.6$ years. Furthermore, the mean number of years that FDs were employed by or affiliated with their current institution was $12.4 \pm 7.4$ years. All training, research, education, and demographic data are summarized in Table 1 .

The medical schools most commonly attended by orthopaedic foot and ankle FDs were Harvard Medical School $(\mathrm{n}=3)$ and Georgetown University School of Medicine $(\mathrm{n}=3)$. Case Western Reserve University School of Medicine, The George Washington University School of Medicine and Health Sciences, The Thomas Jefferson University Sidney Kimmel Medical College, and The University of Utah School of Medicine each educated 2 FDs. All medical schools that trained at least 2 current FDs are included in Fig 1. 
Table 2. Research Profiles of 10 Most Accomplished Orthopaedic Foot and Ankle FDs Based on Scopus $h$-Index, Total Number of Publications, and Total Number of Citations

\begin{tabular}{|c|c|c|c|c|}
\hline \multirow[b]{2}{*}{ FD Name } & \multicolumn{4}{|c|}{ Foot and Ankle FD Research Productivity } \\
\hline & $\begin{array}{c}\text { Scopus } \\
h \text {-Index }\end{array}$ & $\begin{array}{l}\text { Total No. of } \\
\text { Publications }\end{array}$ & $\begin{array}{c}\text { Total No. of } \\
\text { Citations }\end{array}$ & Fellowship Program Name \\
\hline David Thordarson, M.D. & 37 & 210 & 4,459 & Foot and Ankle Institute at Cedars-Sinai \\
\hline Judith Baumhauer, M.D., M.P.H. & 35 & 145 & 3,652 & University of Rochester \\
\hline Steven Raikin, M.D. & 32 & 165 & 3,140 & Thomas Jefferson University Hospital \\
\hline James DeOrio, M.D. & 29 & 140 & 2,994 & Duke University Medical Center \\
\hline Stephen Conti, M.D. & 26 & 62 & 2,513 & University of Pittsburgh \\
\hline James Brodsky, M.D. & 26 & 80 & 2,307 & Baylor University Medical Center \\
\hline Michael Brage, M.D. & 26 & 55 & 1,610 & University of Washington School of Medicine \\
\hline Kenneth Hunt, M.D. & 21 & 85 & 1,255 & University of Colorado \\
\hline Gregory Guyton, M.D. & 21 & 60 & 1,441 & Medstar Union Memorial Hospital \\
\hline Mark Drakos, M.D. & 21 & 105 & 1,722 & Hospital for Special Surgery \\
\hline Timothy Beals, M.D. & 21 & 44 & 1,225 & University of Utah \\
\hline
\end{tabular}

FD, fellowship director.

*As of January 1, 2020.

The 3 orthopaedic residency programs that trained and educated the most future orthopaedic foot and ankle FDs were Harvard Combined Orthopedic Residency Program $(\mathrm{n}=3)$, Carolinas Medical Center Orthopedic Residency Program $(\mathrm{n}=2)$, and University of North Carolina Hospitals $(\mathrm{n}=2)$. All orthopaedic residency programs that trained at least 2 current FDs are included in Fig 2.

The 3 orthopaedic foot and ankle fellowship programs that trained and educated the most future orthopaedic foot and ankle FDs were those at OrthoCarolina Foot $\&$ Ankle Institute $(\mathrm{n}=5)$, Mercy Medical Center $(\mathrm{n}=4)$, and Union Memorial Hospital $(\mathrm{n}=3)$. All orthopaedic fellowship programs that trained at least 2 current FDs are included in Fig 3.

In total, 4 FDs $(8.5 \%)$ obtained their medical education abroad, 2 FDs $(4.2 \%)$ completed their residency abroad, and 3 FDs $(6.4 \%)$ completed their foot and ankle fellowship outside of the United States. Additionally, 1 FD $(2.1 \%)$ was a doctor of osteopathic medicine whereas $46(97.9 \%)$ were doctors of medicine.
Regarding institutional loyalty, 8 FDs (17.0\%) are currently directing fellowship programs affiliated with the medical school they attended. Furthermore, a total of 11 FDs $(23.4 \%)$ are currently directing fellowship programs where they completed residency training. It is interesting to note that 10 FDs $(21.3 \%)$ are currently directing the program in which they underwent fellowship training.

Pearson correlation coefficient calculations revealed a nonsignificant, weak positive correlation between the number of years as an FD and the Scopus $h$-index $(r=0.16, P=.43)$ and a significant moderate positive correlation between the FD age and the Scopus $h$-index $(r=0.61, P=.001)$. Fig 4 presents an overview of the Scopus $h$-index findings.

\section{Discussion}

Overall, this study found that orthopaedic foot and ankle FDs are predominantly white men in their early 50s with strong research achievements. Furthermore, current FDs have served in their capacity for 6 years on

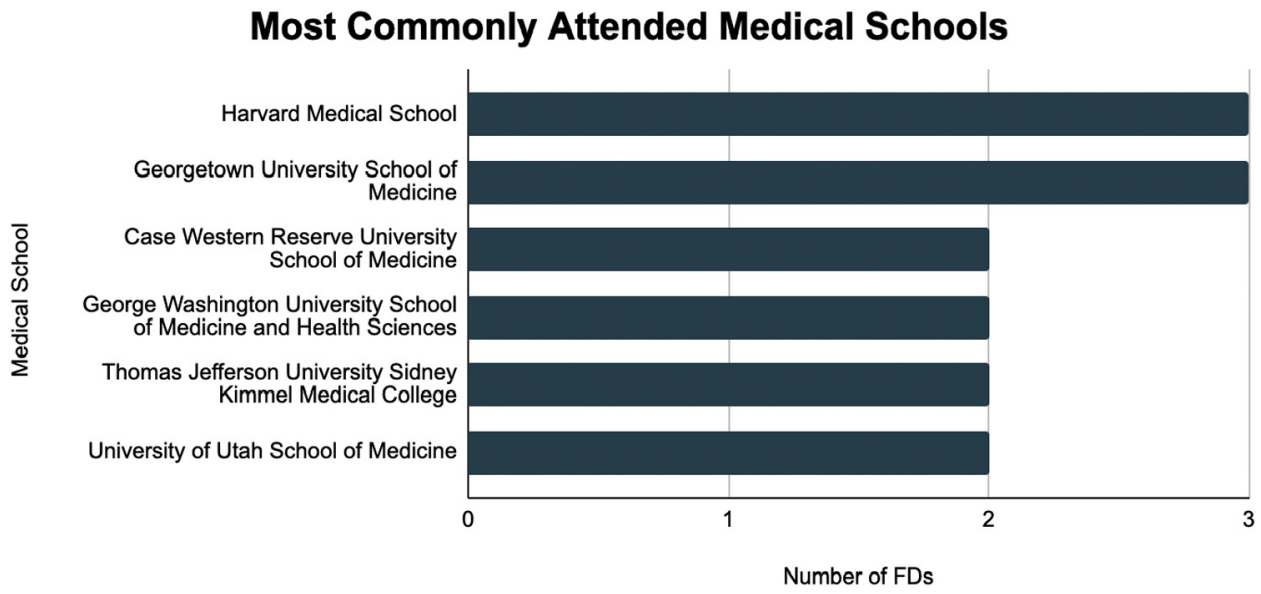

Fig 1. Most frequently attended medical schools for current orthopaedic foot and ankle fellowship directors (FDs). All medical schools with a minimum of 2 previous foot and ankle FD graduates are included. 
Fig 2. Most frequently attended residency training programs for current orthopaedic foot and ankle fellowship directors (FDs). All residency training programs with a minimum of 2 previous foot and ankle FD graduates are included.
Most Commonly Attended Residency Training Institutions

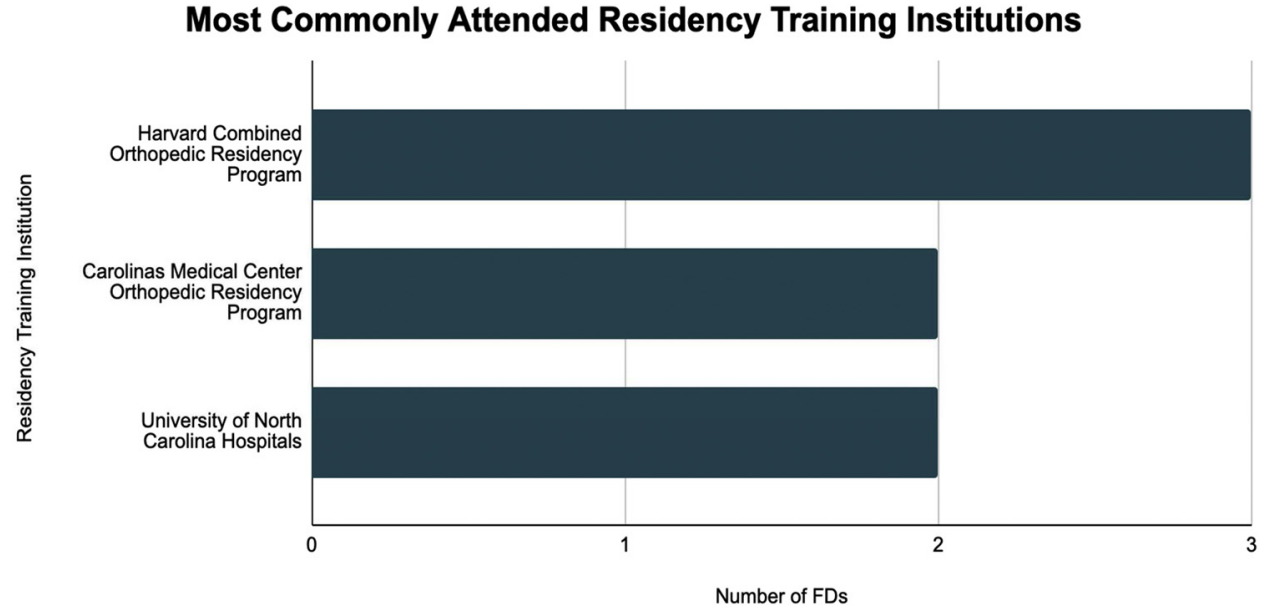

average and were appointed directors approximately 12 years after completing fellowship training. Over half of FDs remain at the institutions at which they completed their medical education, residency, or fellowship.

Orthopaedic surgery has been found to have the lowest proportion of female residents when compared with other surgical specialties. ${ }^{23}$ Furthermore, although female representation in orthopaedics has been increasing over time, the rate of growth within orthopaedic surgery is far lower than in other surgical specialties. From 2006 to 2017, orthopaedic surgery witnessed a $27.3 \%$ increase in female representation whereas neurosurgery and thoracic surgery had increases of $56.8 \%$ and $111.2 \%$, respectively. ${ }^{23}$ It has also been shown that women are less likely to hold department chair positions and high academic appointments when compared with their male colleagues. In the 2015-2016 academic year, it was reported that $8.7 \%$ of professors of orthopaedic surgery were women and there was only 1 female department chair. ${ }^{23}$
Considering the current rate of growth in female representation within orthopaedic surgery, it will take approximately 85 years for women to reach just $30 \%$ representation in the field. ${ }^{24}$

The findings of this study of foot and ankle FDs were consistent with reports that show low female representation within orthopaedic surgery faculty and leadership. Of the 47 FDs, only $3(6.4 \%)$ were women. However, this is a higher rate of female representation in fellowship leadership when compared with other orthopaedic subspecialties. A study inspecting leadership trends of orthopaedic spine FDs found that 3.9\% of FDs were women, ${ }^{15}$ and a similar study looking at adult reconstruction FDs found no female FDs. ${ }^{16}$ Although the orthopaedic foot and ankle specialty has a higher percentage of female FDs in comparison to other specialties, there is still a great deal of progress to be made until equal representation is achieved.

Regarding racial and ethnic diversity, this study found that only $10.6 \%$ of FDs were non-white, which aligns

\section{Most Commonly Attended Fellowship Training Institutions}

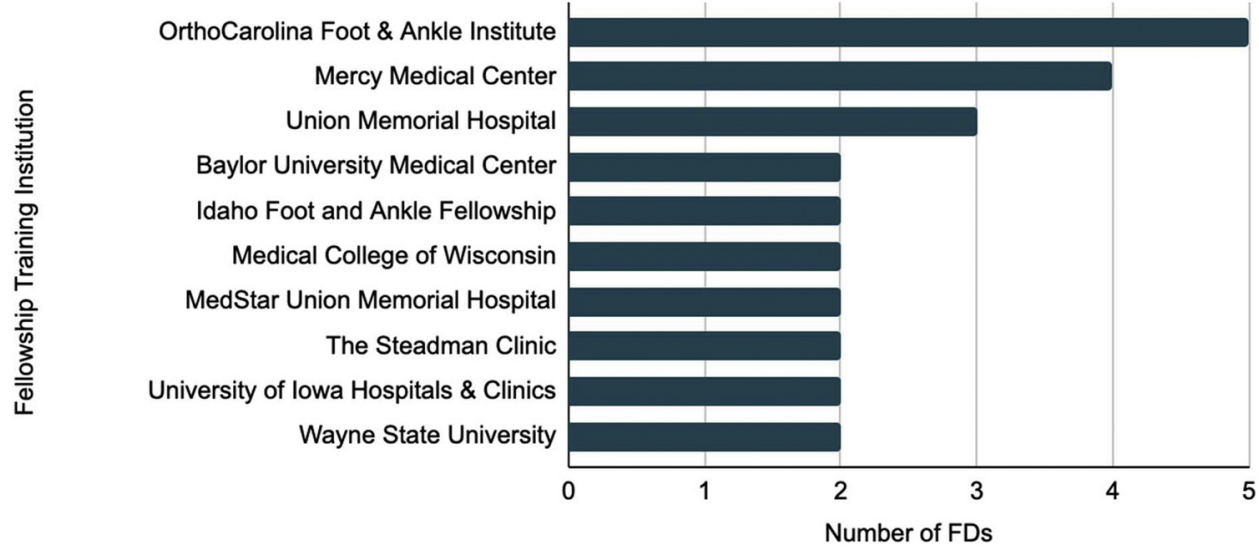

Fig 3. Most frequently attended fellowship training programs for current orthopaedic foot and ankle fellowship directors (FDs). All fellowship training programs with a minimum of 2 previous foot and ankle FD graduates are included. 


\section{H-Indices of Fellowship Directors}

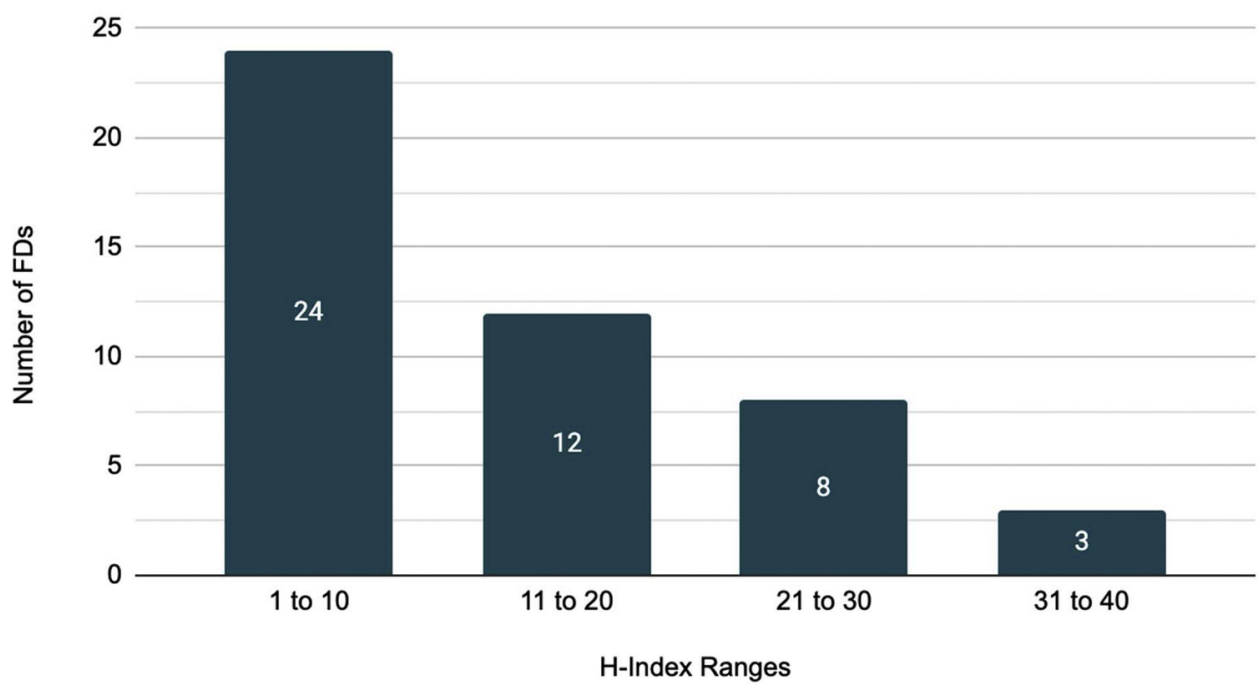

Fig 4. Overview of Scopus $h$ indices (as of January 1, 2020) for all orthopaedic foot and ankle fellowship directors (FDs). with the general trend in orthopaedics. Of the $10.6 \%$ non-white FDs, $8.5 \%$ were Asian and $2.1 \%$ were black or African American. Similarly to female representation in orthopaedics, the rate of ethnic and racial minority representation in orthopaedics has lagged behind that in other surgical specialties. ${ }^{25}$ A study by Poon et al. ${ }^{26}$ even suggested that minority representation in orthopaedic surgery has declined by over 32\% between 2006 and 2015. Comparatively, minority representation has increased $1.2 \%$ in neurosurgery, increased $4.0 \%$ in ophthalmology, and decreased $5.4 \%$ in urology. Only general surgery and obstetrics and gynecology had similar declines in minority representation, at $-26.7 \%$ and $-28.0 \%$, respectively. ${ }^{26}$ Mentorship and early exposure play a significant role in increasing diversity within orthopaedics. Several programs have been working to increase diversity in orthopaedics through mentorship and shadowing opportunities to premedical and medical students. One program, Nth Dimensions, has been shown to increase the odds of applying to orthopaedic residency for under-represented minorities and women. ${ }^{27}$ Thus, minority-focused mentorship and education programs appear to be promising strategies for establishing a more diverse workforce and leadership community in orthopaedic surgery.

An interesting finding in this study pertained to the percentage of FDs possessing international or osteopathic degrees. According to the data, $8.5 \%$ of FDs completed medical school abroad, $4.2 \%$ completed their residency abroad, and $6.4 \%$ completed their fellowship abroad. Furthermore, 1 FD $(2.1 \%)$ was a doctor of osteopathic medicine. According to the Association of American Medical Colleges, $4.9 \%$ of active orthopaedic surgeons were international medical graduates in 2019, which was the second lowest percentage for any specialty. Similarly, $5.6 \%$ of practicing orthopaedic surgeons in 2019 were doctors of osteopathic medicine. ${ }^{28}$ Accordingly, the rate of international and osteopathic backgrounds of orthopaedic foot and ankle FDs appears to accurately reflect the general landscape of practicing orthopaedic surgeons.

Orthopaedic foot and ankle FDs possess impressive research portfolios that are comparable to those in other orthopaedic subspecialties. The mean $h$-index, total number of published documents, and total number of citations among all foot and ankle FDs were 13.5, 47.5, and 898.1, respectively. Furthermore, 23 FDs $(48.9 \%)$ had an $h$-index score of 11 or greater. In comparison, reports of the research backgrounds of FDs in orthopaedic spine surgery and adult reconstruction found mean $h$-indices of 23.8 and 16.5, respectively. ${ }^{15,16}$ Although orthopaedic foot and ankle FDs possess extensive research backgrounds, their research productivity is lower in comparison to leaders in other orthopaedic subspecialties. To provide more context regarding research metrics, a study published in 2017 found that the average $h$-index value for an orthopaedist in an academic chair position was $17.8 .^{29}$ These findings may suggest that, although research is still instrumental in the foot and ankle subspecialty, there exists more opportunity for foot and ankle specialists earlier in their career to achieve an FD position. In the adult reconstruction and spine orthopaedic subspecialties, a significant academic research threshold may be limiting the number of early-career surgeons who are able to lead fellowship programs because robust research portfolios take many years to accumulate. This discrepancy in research experience between these fields may be a result of a significantly lower number of foot and ankle fellowship programs and 
subsequent foot and ankle specialists when compared with the adult reconstruction and spine field.

Regarding institutional loyalty, orthopaedic foot and ankle FDs were considerably more likely to serve as FDs at the institution at which they completed medical school, their residency, or their fellowship. In fact, $23.4 \%$ and $21.3 \%$ of foot and ankle FDs were serving as FDs at the institution at which they completed their residency and their fellowship, respectively. A similar study of FDs in orthopaedic spine surgery found that $13.6 \%$ and $12.6 \%$ served as leaders at the institution at which they completed residency and fellowship training, respectively. ${ }^{15}$ This discrepancy may be a result of the smaller number of orthopaedic foot and ankle fellowships, allowing physicians to establish stronger, more insular networks within their home institutions.

With respect to training pedigree, the institution at which orthopaedic foot and ankle FDs completed their training, especially their fellowship, played a considerable role in attaining the FD position. Although there was a weak association between medical school or residency location and FD attainment, there was a stronger association between fellowship location and appointment as a foot and ankle FD. In fact, over $25 \%$ of all foot and ankle FDs completed their fellowship at 3 institutions: OrthoCarolina Foot $\delta$ Ankle Institute, Mercy Medical Center, and Union Memorial Hospital. Of these 3 institutions, OrthoCarolina Foot \& Ankle Institute accounted for approximately $10.6 \%$ of all foot and ankle FDs. Some factors that may contribute to a select number of institutions producing a significant number of FDs may be extensive research production, leadership-centric institutional culture, premier networking opportunities, and institutional histories with alumni who are leaders in the orthopaedic foot and ankle field.

\section{Limitations}

This study had a few limitations. Primarily, the data collection process depended on retrieving self-reported data on the internet, whether in the form of website biographies or CVs. It is possible that information reported on an institutional website or on a CV may be outdated at the time of data collection; however, we limited discrepancies by obtaining information from sources that were not publicly editable, by clarifying ambiguous information with e-mails to fellowship representatives or directly to FDs, and by corroborating pieces of information from multiple sources. Additionally, several attempts to reach fellowship administrators and FDs were unsuccessful, resulting in select gaps in the data. All data points as outlined in the "Methods" section were not able to be found or obtained for $100 \%$ of FDs. Overall, 26 FDs $(55.3 \%)$ had complete data whereas the remaining 21 FDs had nearly complete or partially complete data. Therefore, some pieces of data with lower response rates may be less representative of the entire orthopaedic FD population. Finally, these data represent a cross-sectional representation of orthopaedic foot and ankle FDs at a single point in time.

\section{Conclusions}

Orthopaedic foot and ankle FDs are primarily white men in their 50s, with minimal female and minority representations. These FDs are distinguished by their high level of research productivity. Additionally, orthopaedic foot and ankle training backgrounds seem to play an important role, given that most of the appointed FDs trained in only a few select programs.

\section{References}

1. Daniels AH, DiGiovanni CW. Is subspecialty fellowship training emerging as a necessary component of contemporary orthopaedic surgery education? J Grad Med Educ 2014;6:218-221.

2. Ruddell JH, Eltorai AEM, DePasse JM, et al. Trends in the orthopaedic surgery subspecialty fellowship match: Assessment of 2010 to 2017 applicant and program data. J Bone Joint Surg Am 2018;100:e139.

3. Yayac M, Javandal M, Mulcahey MK. Accredited orthopaedic sports medicine fellowship websites: An updated assessment of accessibility and content. Orthop J Sports Med 2017;5:2325967116683942.

4. Horst PK, Choo K, Bharucha N, et al. Graduates of orthopaedic residency training are increasingly subspecialized: A review of the American Board of Orthopaedic Surgery Part II database. J Bone Joint Surg Am 2015;97: 869-875.

5. Baweja R, Kraeutler MJ, Mulcahey MK, et al. Determining the most important factors involved in ranking orthopaedic sports medicine fellowship applicants. Orthop J Sports Med 2017;5:2325967117736726.

6. Grabowski G, Walker JW. Orthopaedic fellowship selection criteria: A survey of fellowship directors. J Bone Joint Surg Am 2013;95:e154.

7. Kavolus JJ, Matson AP, Byrd WA, et al. Factors influencing orthopedic surgery residents' choice of subspecialty fellowship. Orthopedics 2017;40:e820-e824.

8. Matson AP, Kavolus JJ, Byrd WA, et al. Influence of trainee experience on choice of orthopaedic subspecialty fellowship. J Am Acad Orthop Surg 2018;26:e62-e67.

9. Rao RD, Khatib ON, Agarwal A. Factors motivating medical students in selecting a career specialty: Relevance for a robust orthopaedic pipeline. J Am Acad Orthop Surg 2017;25:527-535.

10. Schrock JB, Kraeutler MJ, Dayton MR, et al. A crosssectional analysis of minimum USMLE step 1 and 2 criteria used by orthopaedic surgery residency programs in screening residency applications. J Am Acad Orthop Surg 2017;25:464-468.

11. Filiberto AC, Le CB, Loftus TJ, et al. Gender differences among surgical fellowship program directors. Surgery 2019;166:735-737. 
12. Ford KR, Myer GD, Hewett TE. Valgus knee motion during landing in high school female and male basketball players. Med Sci Sports Exerc 2003;35:1745-1750.

13. Rohde RS, Wolf JM, Adams JE. Where are the women in orthopaedic surgery? Clin Orthop Relat Res 2016;474: 1950-1956.

14. Addona T, Polcino M, Silver L, et al. Leadership trends in plastic surgery. Plast Reconstr Surg 2009;123:750-753.

15. Donnally CJ, Schiller NC, Butler AJ, et al. Trends in leadership at spine surgery fellowships. Spine 2020;45: E594-E599.

16. Schiller NC, Donnally CJ, Sama AJ, et al. Trends in leadership at orthopedic surgery adult reconstruction fellowships. J Arthroplasty 2020;35:2671-2675.

17. American Orthopaedic Foot \& Ankle Society. Orthopaedic foot and ankle fellowship programs. https://Www.aofas.or g/education/fellowship-match-program/orthopaedic-foo t-and-ankle-fellowship-programs. Accessed December 20, 2020.

18. SF Match-Residency and Fellowship Matching Services. Residency and fellowship match. https://sfmatch.org/ SubSpecialties.aspx?id=32\&typ $=1$. Accessed November 23, 2020.

19. Welzenbach R. Research guides: Research impact metrics: Citation analysis: H-Index. https://guides.lib.umich.edu/c. php? $g=282982 \& p=1887449$. Accessed November 23, 2020.

20. Scopus. Scopus Preview. Welcome to Scopus. https://www. scopus.com/home.uri?zone $=$ headerforigin $=$. Accessed November 23, 2020.

21. Mukaka MM. Statistics corner: A guide to appropriate use of correlation coefficient in medical research. Malawi Med J 2012;24:69-71.
22. Schober P, Boer C, Schwarte LA. Correlation coefficients: Appropriate use and interpretation. Anesth Analg 2018;126:1763-1768.

23. Chambers CC, Ihnow SB, Monroe EJ, et al. Women in orthopaedic surgery: Population trends in trainees and practicing surgeons. J Bone Joint Surg Am 2018;100: el 16.

24. Brown MA, Erdman MK, Munger AM, et al. Despite growing number of women surgeons, authorship gender disparity in orthopaedic literature persists over 30 years. Clin Orthop Relat Res 2020;478:1542-1552.

25. Okike K, Phillips DP, Johnson WA, et al. Orthopaedic faculty and resident racial/ethnic diversity is associated with the orthopaedic application rate among underrepresented minority medical students. J Am Acad Orthop Surg 2020;28:241-247.

26. Poon S, Kiridly D, Mutawakkil M, et al. Current trends in sex, race, and ethnic diversity in orthopaedic surgery residency. J Am Acad Orthop Surg 2019;27: e725-e733.

27. Mason BS, Ross W, Ortega G, et al. Can a strategic pipeline initiative increase the number of women and underrepresented minorities in orthopaedic surgery? Clin Orthop Relat Res 2016;474:1979-1985.

28. Association of American Medical Colleges. 2020 Physician specialty data report executive summary. https:// WWw.aamc.org/data-reports/data/2020-physician-speci alty-data-report-executive-summary.

Accessed February 16, 2021.

29. Bastian S, Ippolito JA, Lopez SA, Eloy JA, Beebe KS. The use of the h-index in academic orthopaedic surgery. J Bone Joint Surg 2017;99:e14. 